\title{
APSA Fellowship with the Congressional Research Service
}

Anthony Madonna, The University of Georgia

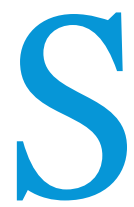

erving as an APSA Congressional Fellow had been a goal of mine since I started graduate school. The fellowship provided an opportunity to examine the congressional policy-making process first hand. And while I had worked on congressional campaigns, in state legislative offices, and supervised student internships, I had no direct experience working on Capitol Hill for Congress. In addition, the program was highly recommended by senior colleagues who had served as fellows themselves. Nearly all of them had worked on the staffs of individual congressional members and found the experience served to better inform both their research and teaching. When I found out I would be serving as a fellow for the 2012-13 academic year, my plan was to spend that year in a congressional member office as well.

In addition to House or Senate member offices, the two-month fellowship orientation exposed me to other types of assignments fellows could receive. This included working for committees in either chamber, as well as legislative and executive branch agencies, like the Environmental Protection Agency, Congressional Budget Office, Centers for Disease Control and Prevention, and Congressional Research Service, among others. Settling on a type of assignment was difficult, as each one had its own advantages. To make an informed decision on this question, I did what I do best: relentlessly hassled more knowledgeable people for advice. ${ }^{1}$ This included former fellows, undergraduate students, other political scientists, and friends from college and graduate school working on the Hill.

While there was substantial variance among assignments, the advantages of working in a House or Senate member office were clear. These positions would broaden my understanding of Congress by giving me more exposure to constituency and policy work. Additionally, they would help clarify my working knowledge of day-to-day congressional office behavior. This would be valuable, as I had very little background in any of these areas. I was, however, a little concerned that I would not have enough access to get a complete picture of office operations.

The value of an agency assignment-especially one with the Congressional Research Service (CRS) -was fairly obvious. At this point in my career, my research has primarily examined two specific areas within the broader issue of American political institutions: the intersection between congressional rules and policy output and executive-legislative interactions. Like most political scientists who have worked in these areas, I had often relied on CRS reports to better inform my work. A placement at CRS would allow me to meet many scholars whose work I was familiar with and greatly appreciated. After interviewing

Anthony Madonna is an assistant professor in the department of political science at the University of Georgia. He can be reached at ajmadonn@uga.edu. with scholars from the Legislative Process section of CRS, I felt more convinced of the value of such a placement and accepted the position.

\section{THE CONGRESSIONAL RESEARCH SERVICE}

The mission of CRS is to serve "Congress throughout the legislative process by providing comprehensive and reliable legislative research and analysis that are timely, objective, authoritative and confidential, thereby contributing to an informed national legislature."2 For analysts working in my section, this necessitates balancing both long-term and short-term projects. In the short-term, this includes teaching courses on legislative process to staffers, meeting with offices to discuss specific issues, answering phone calls and e-mails, and drafting memos. Longer-term projects, which often stem from short-term requests, involve updating reports and pamphlets.

The classes provide a detailed look at specific elements of House or Senate procedure. For instance, courses include topics like the amending process, House special rules, cloture, forming unanimous consent agreements in the Senate, and committee procedures. When requested, analysts will present these topics to specific staff offices. These courses vary in length and often involve a lengthy question-and-answer period.

Sitting in on these lectures has been extremely valuable. For example, for the past three years I have worked with undergraduates at the University of Georgia to collect data on the amending process to better evaluate the effects of institutional decisionrules on policy output. Although a good amount of this coding is routine, a number of complicated questions involving the amending process have come up. On several occasions, these topics were also mentioned during the CRS courses and led me to reevaluate my coding scheme.

\section{MY DUTIES}

In addition to attending lectures and sitting in on the occasion meeting with staff, I provide research assistance to analysts working on various requests and projects. This has been helpful for me in a number of anticipated and unanticipated ways. First, serving as a research assistant has helped broaden my knowledge of legislative process and procedure. Although this is an area I have worked in as a political scientist, I did so in a somewhat narrow fashion. The publishing process incentivizes assistant professors to specialize. Because of this, most of my work had focused on obstruction in the US Senate. As a consequence, my understanding of committee behavior, scheduling, and floor procedure was comparatively quite limited. By helping on various assignments when they come up, I have been exposed to a number of procedures and legislative behavior I had little to no knowledge of before my placement. 
The research assistance has also exposed me to new data sources. For example, I have worked on projects examining questions of order in the US Senate, chamber recesses, and the usage of conference committees, among others. All of these projects have taken me out of my comfort zone as an academic. They have required me to consult new reports, different data sources, or virtual references. I hope to use these tools when I continue my political science research after I leave CRS. systematic bias associated with identifying only those filibusters manifested on the floor. As such, debates over whether a specific case was evidence of a filibuster on the underlying issue are likely a distraction from the main question of interest. Even if there is general agreement that a particular episode constitutes a filibuster, measuring the effect of the obstruction by looking only at the final passage vote, amending activity, or even the content of that specific measure is insufficient because most compromises

\section{Attempting to examine the effect of the Senate's rules by looking at specific filibusters (or cloture votes) often introduces systematic bias associated with identifying only those filibusters manifested on the floor. As such, debates over whether a specific case was evidence of a filibuster on the underlying issue are likely a distraction from the main question of interest.}

My primary duty has been to identify actions that might be considered filibusters that occurred during the 111th (2009-2010) and 112th (2011-2012) Congresses. To do this, I started with a list of all bills, nominations, and motions upon which cloture was filed (an appropriate starting point for this particular time). I then prepared the episode history using the Legislative Information System, Congressional Record, Daily Digest and various newspaper accounts. When completed, I edited episode history into a one to two paragraph entry focusing on the procedural details. Then I offer a recommendation as to whether the episode constituted a possible filibuster and pass the information on to senior analysts. The filibuster project is time-consuming, but immensely interesting and dovetails nicely with my research agenda. It also highlights a problem I have grappled with as a political science: the arbitrary nature of identifying filibusters in the chamber.

Attempting to examine the effect of the Senate's rules by looking at specific filibusters (or cloture votes) often introduces involve a tangential bill or issue dimension. I hope to use my experiences at CRS to better address this issue. By providing a complete legislative history for each episode, I can better identify the policy consequences of the Senate's rules. Specifically, I can get a view of what aspects of a bill are changed as well as what other bills or nominations are altered in response to obstruction.

In addition to experiences stemming from my CRS placement, I am fortunate to have made a number of excellent contacts that I can use in the future. The workplace at CRS is extremely friendly, and I have taken away a great deal from just talking to analysts about Congress.

\section{NOTES}

1. I am especially indebted to Charles Bullock, Elizabeth Rybicki, and James Wallner for their help.

2. http://www.loc.gov/crsinfo/about/history.html 